\title{
Uma estrutura circular para o treinamento físico de atores
}

\author{
Brígida Miranda
}

Universidade do Estado de Santa Catarina

Na primeira metade do século XX, diretores como Konstantin Stanislavsky, Vsevolod Meyerhold, Jacques Copeau e Etienne Decroux adaptaram da esfera militar exercícios de resistência física e esportes de combate, como esgrima e boxe, para treinar fisicamente grupos de atores. Na segunda metade do século XX, a adaptação de artes marciais de origem asiática revitalizou o uso de formas de combate para treinar o corpo do ator. Adolf Clarence Scott e Phillip Zarrilli são figuras-chave na adoção de artes marciais de origem asiática para treinar atores norte-americanos. Scott iniciou um programa em Wisconsin-Madison, em 1963, usando tai-chi-chuan para treinar seus estudantes de graduação (Zarrilli 1993:62). Zarrilli juntou-se a esse programa, na década de 1980 e adaptou exercícios de yoga e kalarippayattu, uma arte marcial do sul de Kerala, na India. Atualmente, desenvolve esse projeto na University of Exeter, na Inglaterra.

A capoeira, conhecida internacionalmente como uma arte marcial brasileira, tem sido adaptada, desde o final dos anos 1970, por figuras centrais na prática teatral, como atividade física no treinamento de atores, assim como elemento de performance. Em 1978, como parte do treinamento individual, dois atores do Odin Teatret, Roberta Carreri e Francis Pardeilhan, passaram três meses no Brasil aprendendo capoeira (Barba 1995:6). Na década de 1990, o grupo francês Archaos Cirque usou capoeira como elemento de performance ${ }^{1}$. O Archaos selecionou e trabalhou com um grupo de capoeiristas brasileiros no show Metal Clown (1991-1992).

Artistas brasileiros internacionalmente conhecidos têm adotado elementos da capoeira em seus processos de treinamento. Augusto Boal, por exemplo, sugere o uso da capoeira no treinamento físico de atores (1992:100). Antônio Nóbrega tem também incorporado a capoeira em seu treino individual usando movimentos dela em sua peça teatral Figural (1990) ${ }^{2}$. Marcos Breda, ator brasileiro de teatro e televisão, adaptou em sua interpretação do personagem de commedia dell' arte, Arlequim, a corporalidade da capoeira ${ }^{3}$. Paralelamente, Breda discutiu aspectos da capoeira adaptados a preparação física do ator em sua tese de mestrado realizada na UNIRIO. Enquanto isso, no cinema comercial 
norte-americano os movimentos de capoeira aparecem associados ao corpo da personagem de quadrinhos, Mulher-Gato. A atriz norte-americana Halle Berry explica que treinou capoeira por oito meses com o Mestre Boneco, capoeirista brasileiro com escola em Los Angeles, para realizar as seqüências de luta de sua personagem no filme Catwoman ${ }^{4}$.

Há, contudo, alguns pontos que precisam ser considerados quando usamos exercícios derivados de artes marciais para treinar fisicamente atores de teatro. Acredito que um dos problemas na adaptação de artes marciais para treinar atores é que muitas dessas artes têm sido historicamente praticadas quase que exclusivamente por homens. Quando consideramos a possibilidade de treinar atores teatrais, é necessário estarmos conscientes dos elementos militares e de orientação masculina no cerne das artes marciais e, então, buscar caminhos para adaptá-los a uma prática informada pelos estudos de gênero. A prática contemporânea de capoeira, tanto no Brasil como em outros países, não chega a ser necessariamente diferente de espaços de treinamento de outras artes marciais, considerada a questão da dominação masculina. Mas, acredito que há certas estruturas que facilitam uma divisão mais igualitária de poder, algumas privilegiam a subversão de hierarquias e promovem uma circulação de poder.

A capoeira tem uma estrutura de treinamento que eu acho particularmente interessante quando consideramos o treinamento de grupos: trata-se da roda de capoeira. O que nós costumamos ver em espaços públicos, como praças, ruas e salões, é uma performance de rua, uma demonstração de capoeira. Mas, a roda de capoeira carrega, ainda, outros significados e objetivos. A roda de capoeira é a estrutura tradicional de treinamento dessa prática social. É uma reunião onde o conhecimento é passado por meio da participação ativa em funções e posições multivalentes. Nessa comunicação, quero apresentar a roda de capoeira como uma estrutura de treinamento que favorece uma constante circulação de posições e funções. Assim sendo, considero que a estrutura da roda de capoeira, potencialmente, aborda questões de gênero, tais como distribuição de poder e função dentro do grupo e o exercício de liderança em uma estrutura coletiva.

A capoeira desenvolveu-se como uma prática escrava no Brasil. As primeiras referências à capoeira datam do século dezessete. Nas ultimas décadas, muitos acadêmicos têm desenvolvido estudos históricos e etnográficos, leituras sociológicas e políticas da prática de capoeira no Brasil. Os escritos de Carlos Eugênio Líbano Soares, Letícia Vidor Reis, Júlio Cesar de Souza Tavares, 
Roberta Matusumoto, J. Lowell Lewis e Barbara Browning têm argumentado que a capoeira desenvolveu-se como "prática de resistência" contra o sistema escravocrata e como uma forma de reconstrução da identidade cultural e étnica, que se tornou uma identidade afro-brasileira. Muitos sustentam que a capoeira ainda é uma prática de resistência e, como tal, pode ser adaptada e reinventada por minorias no Brasil e em outros países.

A roda de capoeira consolidou-se, ao longo do tempo, como uma estrutura eficaz de treinamento em espaços abertos na cidade. Browning sustenta que a roda de capoeira funcionou, em um primeiro momento, como um espaço de proteção. Ela argumenta que "a roda de capoeira ostensivamente começou como um pequeno círculo fechando os capoeiristas que estavam em treinamento num processo de transmissão organizada de técnicas de resistência" (1995:95) [tradução da autora]. Na sua prática contemporânea, a roda de capoeira aceita, assim como usa, a visibilidade e contato com não capoeiristas para testar, demarcar e consolidar o treinamento dentro da comunidade. A roda de capoeira é um treinamento físico e rítmico que engloba atividades sociais, celebratórias e ritualísticas. Tanto em ambientes abertos como fechados, a roda apenas acontece quando corpos ativos demarcam o espaço com sua corporalidade física, rítmica, emocional e espiritual.

Ao observar uma roda de capoeira, podemos ver que há capoeiristas envolvidos em diferentes atividades. Há capoeiristas tocando instrumentos e um cantador-solo, compondo, assim, o grupo musical. No meio do círculo, há dois capoeiristas engajados no combate físico ou no ‘jogo' como dizem na capoeira, ao invés de lutar ou brigar. Um grupo maior de capoeiristas reúne-se em volta dos dois jogadores criando e delineando o círculo com seus corpos. Este grupo exercita muitas atividades ao mesmo tempo. Eles são o coro, à medida que respondem, cantando, aos chamados do cantador-solo e, também, marcam o ritmo com palmas, respondendo ao ritmo criado pelos instrumentos do grupo musical. Observam a conversa física que está acontecendo no centro da roda, observam o jogo. Enfim, as principais atividades exercitadas na roda de capoeira são: tocar instrumentos, jogar fisicamente, ser um espectador ativo, ao observar, cantar e marcar o ritmo coletivamente.

Esta estrutura de treinamento pode exercitar mais que habilidades físicas, como cantar, tocar, expressividade corporal e capacidade de estabelecer conversas corporais e musicais. É uma forma não regimentada de treinamento físico. Ela retira os corpos das filas, das repetições, das rotinas de exercícios. Treina o processo criativo de contar histórias, a improvisação física e uma 
participação ativa em todos os níveis, incluindo o de espectador.

Porém, eu gostaria de chamar a atenção para algo mais que pode ser treinado por meio desta estrutura. A roda de capoeira exercita a circulação de funções, à medida que permite aos capoeiristas completa mobilidade do coro/espectador ao músico e ou jogador físico. No que diz respeito à prática teatral, a mobilidade da roda oferece um desafio ao processo onde o diretor ou diretora observa e dirige sem comprometer sua própria fisicalidade. A relação entre mestre e coletivo sugere que professores/treinadores/diretores podem estar fisicamente engajados no treinamento. Isto pode ajudar a mudar a relação entre diretor-ator, que é baseada na idéia de que o ator é o corpo/instrumento e o diretor, a mente/controlador.

A liderança da roda de capoeira é normalmente assumida pelo mestre, ou pela pessoa responsável pela organização do treinamento. Mas, é importante notar que, na dinâmica circular da roda de capoeira, a liderança da roda é, na verdade, um papel ou função não fixa. Durante a roda de capoeira, mesmo o berimbau principal, portanto, o instrumento de liderança da roda, pode ser tocado por outros participantes do treino.

Em uma roda de capoeira, o mestre freqüentemente passa seu berimbau e liderança do grupo musical para outro jogador. Embora o mestre não deixe de ser mestre, que é seu título, ele ou ela não desempenha a função de liderança todo o tempo. Como qualquer outro jogador, o mestre circula e joga em diferentes funções no evento coletivo da roda. Por exemplo, o mestre pode participar do que é chamado 'um jogo'.

Nessa dinâmica, os atores ou jogadores não param de atuar ou jogar, mas são guiados pelo instrutor. Similarmente, na estrutura da roda de capoeira, o líder é integrado ao treino e/ou apresentação. Ele instrui os jogadores por meio de comandos verbais e musicais. O líder pode instruir os jogadores pela letra da música. As letras em capoeira são abertas à improvisação e essa flexibilidade é um estímulo à criatividade poética do líder ao conduzir o treinamento.

Em capoeira, quando o mestre ou líder original da roda está jogando, ele ou ela cria uma situação em que a própria liderança fica aberta a ser exercitada por outros jogadores. Pode ser sustentado que a roda de capoeira, potencialmente, treina qualquer indivíduo do grupo para assumir a liderança da roda, como também, treina o grupo para aceitar essa liderança. Essas mudanças de lugar e função na roda de capoeira podem promover uma redistribuição e circulação de poder. A roda de capoeira oferece um modelo de liderança que e 
potencialmente mais flexível e democrático.

A estrutura de liderança e comunicação na roda de capoeira pode ser comparada à estrutura de treinamento e ensaio de "sidecoaching" (instrução) de Viola Spolin (1985:9-10). Em ensaios, Spolin sugere não apenas a integração do diretor à cena, mas, também, "phrases" (frases) que o "sidecoach" (instrutor) fala, como (contato) ou "contact" or "share your voice with the audience!" (compartilhe sua voz com a platéia) (ibid) [itálico do original; tradução da autora].

Esta estrutura pode inspirar alternativas para lidar com dificuldades vividas por diretoras quando estas assumem funções de liderança e direção na prática teatral. Interessada em como o gênero molda as maneiras de trabalhar no teatro ocidental contemporâneo, Rebecca Daniels (1996) entrevistou trinta e cinco reconhecidas diretoras de teatro norte-americanas, incluindo Anne Bogart. Daniels discute como, apesar do considerável nível de consciência sobre questões de gênero, as diretoras têm uma forma diferente de exercer o papel de 'diretor'. Sua pesquisa apontou que diretoras experienciam dificuldades pessoais ao assumirem posições de poder e liderança no teatro - um teatro que tem sido moldado principalmente por homens como diretores. Há algumas tendências ou padrões de trabalho que distinguem as diretoras norte-americanas de seus colegas homens. Um desses padrões, indicado por Daniels, é a tendência de trabalhar colaborativamente (1996:90). Bogart ainda sente-se desconfortável ao assumir a função de direção:

Eu sinto que porque eu sou uma mulher que eu me insinuo no processo, ao invés de dirigir o processo. Porque eu sou uma mulher, eu lido com mais dúvidas como diretora porque dirigir é uma relação de poder. [...] Eu acho muito dificil assumir o poder. (Bogart citada em Daniels 1996:83) [tradução da autora]

A roda de capoeira mostra que liderança pode ser treinada. Também mostra que mesmo as mais extenuantes práticas físicas podem ter um tipo de liderança que é fluida, temporária e que serve às dinâmicas de práticas coletivas. Eu acredito que a roda de capoeira, como uma estrutura de treinamento físico, pode encaixar-se nas estruturas de trabalho preferidas, por diretoras e outras mulheres envolvidas com o fazer teatral. 


\section{Referências}

BARBA, Eugenio. The Paper Canoe: A Guide to Theatre Anthropology. London. Routledge. 1995.

BRAUN, Edward. Meyerhold: A Revolution in Theatre. London. Methuen. 1995. BROWNING, Barbara. Samba: Resistance in Motion. Bloomington. Indiana UP. 1995.

BUTLER, Judith. Gender Trouble: Feminism and the Subversion of Identity. New York. Routledge. 1999.

CARNICKE Sharon Marie. Stanislavsky in Focus. Amsterdam. Harwood Academic Publishers. 1998.

DANIELS, Rebecca. Women Stage Directors Speak: Exploring the Influence of Gender on Their Work. Jefferson, NC. McFarland \& Co.. 1996.

HODGE, Alison, ed. Twentieth Century Actor Training. London. Routledge. 2000.

LEWIS, John Lowell. Ring of Liberation: Deceptive Discourse in Brazilian Capoeira. Chicago. The University of Chicago Press. 1992.

MATSUMOTO, Roberta K. "Capoeiras Angola E Regional: Duas Formas De Entendimento E De Integração 'a Sociedade Brasileira”. In Entre Áfricas E Brasis. Brasília. Paralelo 15, pp. 135-50. 2001.

REIS, Letícia Vidor de Sousa. O Mundo De Pernas Para O Ar: A Capoeira No Brasil. São Paulo: Publisher Brasil. 1997.

SCOTT, A. C. (Adolphe Clarence). Reflections on the Background of the Performing and Martial Arts of East Asia. In Asian Martial Arts in Actor Training. Madison. Center for South Asian Studies, University of Wisconsin-Madison, pp. 31-37. 1993.

'Underneath the Stew Pot, There's the Flame...' T'ai Chi Ch'uan and the Asian/Experimental Theatre Program". In Asian Martial Arts in Actor Training. Madison. Center for South Asian Studies, University of Wisconsin-Madison, pp. 48-61. 1993.

SOARES, Carlos Eugênio Líbano. A Capoeira Escrava e Outras Tradições Rebeldes no Rio de Janeiro (1808-1850). Campinas, SP. Editora da Unicamp, Centro de Pesquisa em História Social da Cultura. 2001.

A Negrada Instituição: Os Capoeiras no Rio de Janeiro 1850/1890. Rio de Janeiro. Secretaria Municipal de Cultura, Departamento Geral de Documentação 
e Informação Cultural, Divisão de Editoração. 1994.

SPOLIN, Viola. Theater Games for Rehearsal: A Director's Handbook. Evanston, Ill.. Northwestern UP. 1985.

VIERA, Luis Renato. O Jogo De Capoeira: Cultura Popular No Brasil. Rio de Janeiro. Editora Sprint. 1995.

ZARRILLI, Phillip B., ed. Asian Martial Arts in Actor Training. Madison. Center for South Asian Studies, University of Wisconsin-Madison. 1993. (ed.) Acting (Re)Considered: Theories and Practices. London. Routledge. 1995. When the Body Becomes All Eyes: Paradigms, Discourses and Practices of Power in Kalarippayattu, a South Indian Martial Art. Oxford. Oxford UP. 1998. TAVARES, Júlio Cesar de Souza. Dança Da Guerra: Arquivo-Arma. Dissertação de Mestrado. Universidade de Brasília, 1984

Gingando and Cooling Out: The Embodied Philosophies of the African Diaspora. Ph.D. Thesis. The University of Texas. 1998.

\section{Notas}

1 Metal Clown.

$<\underline{\text { http://www.archaos-cirque.com/creations/metal.html }>12 / 06 / 2003}$

2 "Aula Espetáculo (Sol a Pino)."

$<$ http://www.antonionobrega.com.br/> 12/06/2003

"O Artista."

< $\underline{\text { http://www.antonionobrega.com.br/ }>12 / 06 / 2003 ~}$

"Figural (Ficha Técnica)."

$<$ http://www.antonionobrega.com.br/ $>12 / 06 / 2003$

3 Arlequim, Servidor de Dois Patrões

$<\underline{\text { http://divirta-se.correioweb.com.br/materias.htm?codigo=900\&imprimir=Impressora }>22 / 08 / 2003}$

4 Catwoman (2003). Warner Bros.

$<$ http://www.dance.net $/$ read.html?postid $=2112659$ \& replies $=0$ \&page $=1>22 / 08 / 2003$

$<\underline{\text { http://www.capoeirabrasil.com/ }>22 / 08 / 2003}$ 